\title{
Aşkın İkinci Yüzü: Hüsn, Leyla ve Züleyha'nın Aşkı
}

\section{Bekir Kayabaşı ${ }^{1}$}

\section{Özet}

Edebiyat tarihinde çok sayıda kadın yazar ve şair olduğu söylenemez. Bu çalışmanın amacı “aşk” üzerinde düşünmektir. Bu çalışma özellikle kadının aşkı üzerine odaklanmıştır. Aşk bir insan eylemi olmasına karşın yalnızca erkek yazar ve şairler tarafından kullanılmıştır. Sayısız kitapta bu yazarlar ve şairler erkeğin aşkını konu alırken hissederek, kadının aşkını daima tahmin ederek konu edinmişlerdir.

Bu makalede İslami Edebiyatın üç büyük kadın kahramanı Leyla, Züleyha ve Hüsn'ün aşkları tartışılacaktır. Erkekler tarafından yazılan kitaplarda bu üç kadın kahramanın aşkı nasıl kurgulanmıştır? Erkelerin bakış açısından kadın nasıl âşık olur ve aşkını nasıl ifade eder? Bu sorular bu makalede tartış1lacak.

Anahtar Kelimeler: Aşk, Leyla, Züleyha, Hüsn, Kadın.

\section{Second Face of Love: Husn, Leyla and Zuleyha's Love}

\section{Abstract}

It can not say that planity of women writor and poets there are in every part of literature in History. Aim of this work is thinking about love. This work espacially focus on women's love. Love had been used only the men writors and poets inspide of love is an human act from thousands of years. That's writor and poets had been subjected men's love was feelingly but women's love always had been estimated in numerous books.

In this artical discuss how to be descirebed three bigest women hero's love in Islamic literatüre Leyla, Zuleyha and Husn. -How the love had been constructed for that's tree women hero in boks who were written by men. How women fallen in love and how they had been expressed their love from view of men. That's questions will be discuss in this artical.

Key Words: Love, Leyla, Züleyha, Hüsm, Women

\footnotetext{
${ }^{1}$ Yrd.Doç.Dr., Adıyaman Üniversitesi, Eğitim Fakültesi, İlköğretim Bölümü e-mail: bkayabasi@hotmail.com
} 


\section{GİRIŞ}

Tanımlamak, felsefenin ve mantığın ilk uğraşlarındandır. Mantığın ilk ilkesi olan "özdeşlik" ilkesi gereği her sözcük sadece kendini anlatacak şekilde tanımlanmalıdır (Özlem, 2004) $\mathrm{Bu}$ tanım gerçekleştiğinde tanımlanan sözcüğü cümlemizde sınırları belirlenmiş olarak kullanabiliriz. Aşk böyle bir tanımlama ile izah edilebilir mi? Aşk nedir sorusunun doyurucu, kapsayıcı tanımı mümkün müdür? Birçok sözcük için tanımlanamazlık, eksik izah problemi geçerlidir. Aynı şekilde her dil için "aşk" sözcüğünü tanımlamak kolay görünmemektedir. Kavramın eski olması ve yaygın kullanılmasının yanında insan ontolojisi ile olan bağlantısı, kozmolojik yönü, semavi ve diğer dinlerde sahip olduğu işlev, aşkı, çok bilinen bir bilinmez hâline getirmiştir.

Mevlana divanındaki bir şiirinde şöyle der:

"Aşk nedir sordu biri

Dedim bu konularda bana sorma

Benim gibi olursan bilirsin

O seni çağırınca anlatır hikayesini” ( Chittick, 2008:45)

Tasavvufun sürekli vurguladığı gibi "aşk" yaşantıdır. Bu bakımdan bazı özel, kişiye has ayrıntıları haizdir. Belki de bu yüzden aşkın herkesi tatmin eden bir tanımına ulaşmakta zorlanılmaktadır. Mevlana'nın bu ifadesine mukabil ünlü ilk sufiler "aşk" kelimesini kullanmaktan çekinmiş, aşk yerine "hub" kelimesini tercih etmiştir. Bu tartışmalı yönü aşkın, mezhep ve anlayış farklılıklarına göre yorum ve izahı konusunda da çok büyük değişiklikler göstermesine sebep olmuştur (Uludağ:1991) Bu farklı yollar içerinde "aşk" a sahip çıan ve aşk1 sisteminin ortasına yerleştiren tek düşünce ve inanış sisteminin tasavvuf olduğu düşünülmektedir. Tasavvufun bu kabulü aşkın İslam öncesi dönemden kalma kadın erkek ilişkisi hakkındaki sıkıntılı anlam içeriği tevil edilebilir, yeniden anlamlandırılabilir hâle gelmiştir. Kadın erkek ilişkisi içerindeki bu netameli kısmı İslam inanışı içerisinde gri bölgeye çekmiştir. Böylece "aşk" dinî bir hüviyeti olan, Allah'a ulaşmakta kullanılan bir araca dönüşmüştür. Bu dönüşüm elbette kolay olmamıştır. Cahiliye Arap şiirinin üç temel temasından birisidir aşk (Yalar, 2005). Cahiliye dönemi Arap toplumu ve kadın kimliğini göz önüne aldığımızda aşkın, kahramanlık ve cömertlikle birlikte anılması oldukça anlamlı görülmektedir. Kızını başka bir erkeğe vermektense öldürmeyi tercih eden bir toplumda aşk oldukça tehlikeli bir uğraştır. İslam ile birlikte yasaklanan cahiliye adetleri ile birlikte, ünlü sufi şair İbn Farıd'ın Hamriyye'sine kadar aşk da şiirin konusu olmaktan uzaklaşmıştır. Bu meşhur kaside ile birlikte aşk, eski onurlu yerine oturmuş ve aşkın içeriği dinî anlamlarla dolmuştur. Elbette öncelikle Kuran'dan deliller bulunmuştur: “ İman edenler Allah'ı daha şiddetli severler” (Bakara 2/165) ayetindeki "şiddetli severler" tabiri aşk olarak yorumlanmıştır. 


\section{Her Şey Aşkla Karılmıştır}

“ Her şey aşkla karılmıştır; çünkü onları Allah'ın sevgi sıfatı varlığa getirir ve tüm eylem ve etkilerini o harekete getirir” ( Chittick, 2008:149). Tasavvuf aşk1 yaratılışın birincil muharriklerinden saymaktadır (Arslanoğlu, t.y.:1). Aşk, en itibarlı mevkiini tasavvufta bulmuştur. Bununla birlikte" aşk" İslam düşünce sisteminin bütün mecralarında karşıllı̆g ilan bir kavram olarak tüm İslam düşünürlerinin fikir beyan ettikleri bir alandır. Nitekim ünlü İslam düşünürü İbn Sina bu konuda der ki:

"İmdi demek oluyor ki hakiki( gerçekliği olan ) mevcutlar ya kemalin sonuna ulaşmış yahut tabiatında (zaten) var olan kemali ile başka bir cihetten kendisine bulaşmış olan noksanlık arasında mütereddit bulunan mevcutlardır. Şu hâlde her mevcut kendi kemaline ulaşmayı ve onunla (asla) ayrışmayacak şekilde birleşmeyi arzuladıkça "kemal" ile ve dolayısı ile sevgi ve nefretle münasebette olur. Ayrıca feylesofların izah ettiği üzere kemali veren (ve belirleyen) mebde'nin (kendine mahsus) kemalleri tek tek verdiğini vehmetmek caiz bulunmadığından (Tanrı'nın) kendi hikmeti ve güzel tedbiri sebebiyle ( her mevcudu) külli bir aşka buladığını kabul etmek mutlak gerekli olur" (Birgül, 2000:74).

İbn Sina'nın aşk tanımında Platon'dan etkilendiğini söylemek mümkündür. "Tek güzelden sudur eden güzellik" (K1lıç, 2009) gibi tek kemalden sudur eden kemal. Bütün bir kemalden hissedar olma durumu bize yine Platon'un "küllü ruh” görüşünü anımsatmaktadır. Varlık âleminin bu külli kemalden aldığı hisse, o kemalin tezahürünü aşkın ilk muharrik sebebi olarak görüyor İbn Sina. Buradan hareketle aşk külli kemale bir meyildir denilebilir. Yine İbn Sina'nın yorumundan anlıyoruz ki, külli iradenin arzusu da bu yönde olmalı ki her mevcudu aşka buluyor. Aşk konusunda fikir beyan eden bir çok İslam düşünürü yanında İslam'ın ilk ansiklopedistleri olarak kabul edilen İhvan-1 Safa'nın da aşk hakkında yazdıkları küçük bir risaleleri bulunmaktadır. İhvan-1 Safa'nın 865 sayfalık hacimli külliyatlarında aşk bahsi toplam altı sayfada konu edilmiştir.(Resailu Ihvanu's-safa,ty.:503,506-511) Buna dayanarak, İhvan-1 Safa'da aşk konusunun çok irdelenmediğini düşünülebilir. Bu konuda daha kenarda bir yerde durdukları söylenebilir. Aşkla ilgili en dikkate değer yorumları aşkı her şeyin merkezine koydukları şu birkaç cümledir: "Zira aşk âlemde mevcut (yüce bir olgu ve varlık devam ettikçe asla yok olmayacak ve daima her varlığın tabiatında merkezlenmiş bir kavram olarak kalacaktır" (Birgül, 2000:37).

Aşkla ilgili düşünceler sıralanıp eleştirildikten sonra aşkın tabiat kanunları ile açıklama daha deneysel bir yaklaşımla izahına çalışıldığı görülmektedir. "Böylece aşk sanki toprağa atılan bir tane, henüz yeni dikilmiş bir fidan yahut rahme yeni düşmüş taze nutfe gibi bir şey olur" (Yünügül, 2007:21). Doğada gözlemleyebildiğimiz örneklerle aşk anlaşılır k1lınmaya çalış11ır. 
Başka bir yerde de aşkın doğadaki sebep-sonuç ilişkisini sağlayan muharrik güç olarak tanımlandığını görürüz. "Varlıkların bir kısmı diğer bir kısmının var olmasına sebeptir. İşte bu yüzden ilahi hikmet ve rabbani inayet, kendi varlığına sebep olan varlıklara muhabbet ve meyli, varlıkların tabiatına yerleştirmiştir" (Yünügül, 2007).

Aşkın tanımı diğer bütün tanımlar gibi erkek merkezlidir. Kadın erkek ilişkileri hakkında en eski kaynaklar dini menşeili olanlardır. İnsanoğlu, duygularını tanımlamaya ve isimlendirmeye çok erken dönemlerde başlamıştır. İlk yazılı kaynaklardan olan Sümer tabletlerinde karşılaşıyoruz sevgi üzerine yazılmış sözlere. Yine Sümer krallarının tanrıları İştar'ı onurlandırmak için her yıl yaptıkları evlilik törenlerinden kalma sevgi şiirleri aşkın ve aşkın iade edilişinin ne kadar eski olduğu konusunda bir fikir vermektedir.

Eski Yunan edebiyatının aşk konusundaki birikimi kuşkusuz ulaşılabilecek en değerli kaynaklardandır. Tanrıların insanlar gibi yaşadığı bir kültürde, insanı ilişkiler bütün tanrısal boyutu ile irdelenmiş. İnsanın karşılaştığı bütün sorunlara, felsefenin de banileri olmaları hasebiyle birçok farklı açıdan yaklaşabilmişlerdir. Ama bütün yaklaşımlar erkeklere özel bir akıl yürütmenin sonucudur. Aşkın faydası zararı her zaman erkeği esas alan bir perspektiften değerlendirilmiştir.

Mesela Sokrates'in aşk konusundaki yorumları bize bu alanda 1şı tutabilir. Eflatun'un naklettiği diyaloglardan farklı neticelere varsak da genel itibari ile Sokrates aşkı erkeğin hayatını kötü yönde etkileme ihtimali olan bir maraz olarak görmektedir. Bu bakış açısının altında Yunan mitolojisinin etkisi olduğunu düşünmek için haklı sebepler vardır. Erkekler, dünyada mutlu bir şekilde yaşarken Zeus'a yapılan itaatsizliğin cezası olarak, kadın, dünyaya elinde bir kutu ile gönderilir. Kadının nasıl var edildiği konu ayrı uzun bir hikâye olsa da Yunan mitolojinde, Afrodit'e benzeyen ondan bir şeyler taşıyan kadının elindeki kutuda hastalıklar ve ölüm vardır. Kadın erkeleri o kadar kısa sürede etkiler ki, elindeki kutu ile alakalı bilgilendirilmiş olmalarına rağmen kutunun açılmasını görmezden gelirler. Erkekler, kadın için sonsuz bir yaşamı terk ederler. Bu nedenle olsa gerek Yunan aşk tasavvurunda kadınla erkek ilişkisinde bir ilk günah algısı görmekteyiz. Erkek, kadına inanarak sonsuzluğu ve mutluluğunu kaybetmiştir. Sokrates sürekli uyarır kadın erkek ilişkilerinde dikkatli olunması gerektiğini konusunda elbette erkekleri. Aşkın erkeğe engel olmaması gerektiğini, diğer erkeklerle olan ilişkisine mani olmaması gerektiğini söyler. Aşk erkeğin entelektüel birikimine derinlik katan bir ruhsal durum olmalıdır Sokrates'e göre:

Eski Yunan gibi Orta doğu da erkeklerin kendi aralarında oluşturdukları arkadaş gruplarının sürüklediği bir sosyal hayata sahipti. Kadınların sabit yaşantılarına nazaran daha hareketli olan bu hayat, maceracı ve keşfedicidir. Aşka fazla anlamlar yüklemeyi reddeder. Sokrates'in öz düşünceleri olarak kabul edebiliriz. Buna göre, Sokrates, bilgiye, erdeme ve dostluğa âşık, ama bunların neliği konusunda da çok emin olmayanı diyalektik yöntemle 
hakikati arayan, cinselliğe, cinsel aşka, üremeyi ve türün devamını sağladığı, güzellik aracığıyla üreme arzusu olduğu için (Aydın, 2013: 109) bütünüyle negatif yaklaşır. Ona ölümsüzlük bağlamında bir anlam yükleyen, ama aşırı tutku anlamındaki aşkı insanın gündelik yaşamına zarar verdiği için delilik olarak niteleyip dogmatik temelde buna karşı koyanı tenden çok tine önem veren ve genel anlamda kuşkuları olsa da aşkı insan doğasında eksik olan bir şeyi tamamlamaya dönük bir arzu olarak betimleyen birisi olarak ortaya çıkmaktadır; tensel değil tinsel aşk1 önemsemektedir (Yörükan, 2006: 108-109)

\section{Așk ve Güzellik İlişsisi}

Aşk ve güzellik ilişkisi bir tüme varımdır. İnsanın etrafını gözlemlemesi aşkın oluşumunda tarafların birbirini güzel bulmasının bir beğeninin oluşmasında ön şart olarak değerlendirilebileceği sonucuna ulaşılmasını sağlamıştır. Kuşkusuz "güzel” kelimesinin fiziki ve kültürel algı boyutu birlikte değerlendirilmelidir. Platon'un "güzel” hakkındaki görüşü aşkgüzellik ilişkisinin genel bir kabul düzeyine ulaşmasına neden olmuş gibi görünmektedir. "Başka bir ifade ile dünyadaki güzellikler Mutlak Güzele ulaşmaya kılavuzluk eden değerli basamak taşlarıdır ve Mutlak Güzel daha aşağıdaki bütün güzellere güzelliğini verir ve bu merdivenin en sonunda yer alır. Güzel yaratıklardan, güzel yaşama, güzel yaşamdan, güzel doğrulara ve güzel doğrulardan sonra ise ondan başkasının olmadığ 1 Mutlak Güzelin bilgisine ulaşacaktır ve nihaî güzelliğin ne olduğunu anlaşılacaktır (Taşkent, 2009: 19). Güzellik, kavram olmaktan çıkınca ilahî bir öz haline gelmektedir. İlahî özün ölümlülere ait olması düşünülemeyeceği için, güzellik bir yansıma olarak kabul edilmektedir. Güzellik kavramının var olabilmesi için bir beğeni duygusunun da var olması elzemdir. Beğeniyi besleyen psikolojik, sosyolojik ve dinî kaynaklar güzellik tanımının da şekillenmesinde birincil etkene sahip olmuşlardır. Platon'dan mülhem bütün İslam düşünürleri aşkla güzellik arasında benzer ilintiler kurmaktadırlar. Ruzbihan Bakli bunlardan biridir :"Öyleyse aşk, cemal, güzellik, kemal ve (iyi) huy sahiplerinde olur. Zira aşkın fitratı (mıknatıs) gibi güzellik madenlerini kendine çekmektedir. Aşk her güzeli kendi güzelliğinden yaratanın güzelliği ile müzeyyendir. Kişi Âdem (as) emanet verilmiş emanet güzelliğin insandaki hâli cihetiyle âşık olduğunda tedricen ruhani aşka yükselir. Ruhani aşk, ezeli güzellik madenlerinden ruhların kıvılcımlarıyla ışımıştır" (Birgül, 2000:97)

\section{Aşk'ın Oluşumu}

Aşkın tanımlarından da anlaşılacağı üzere, aşk bir araç olarak görülmektedir. Amaçsa nihai hedef olan Tanrıya ulaşmaktır. Sudurla Tanrıdan uzaklaşan insan her zaman ayrıldığı yere özlem duymaktadır. Mevlana'nın Mesnevi'de ifade ettiği gibi:

"bişnev ez-ney çün şikâyet mî koned / ez-cüdâyîhâ hikâyet mî koned" 
Şikâyet ettiği zaman neyi dinle, belki şikâyet etmiyor, ayrılıkları anlatıyor" (Avşar:2007). Bu ayrılışın acısı insanı hep rencide eder ve insan ayrıldığı yere geri dönmek için daima bir arayış içerisindedir. Bu yükselişin tek yolu aşktır ama aşk için ehil olmak gerekir. Doğuştan bazı özel yetenekler gereklidir. Kays daha bebekken başına gelecekleri hisseder:

508 Ol dem ki bu hâk-dane düşdi

Hâlini bilip figâne düşdi

(Dünyaya gelir gelmez

Hâlini anlayıp ağlamaya başladı)

509 Âhir günini evvel eyleyüp yâd

Ahıtdı sirişk kıldı feryâd

(Önce son gününü hatırlayıp

göz yaşı akıtıp feryat etti)

( Doğan,2014:35)

Leyla vü Mecnun, Hüsn ü Aşk gibi mesnevilerdeki aşk hikâyeleri Kays'ın ve Aşk'ın aşkla yükselişini anlatan hikâyelerdir. Leyla vü Mecnun mesnevisinde Kays'ın nasıl Mecnun'a dönüştüğünü görmek mümkündür. Hüsn ü Aşk'ta da Aşk'1n vurdumduymaz, inanmaz tavrından sıyrılıp, Kays'ı gölgede bırakacak bir aşk ispatı serüvenine tanık olmaktayız. Bu iki hikâyenin sonunda erkek kahramanlar aradıklarını içlerinde bularak, araç olarak kullandıkları aşkla hedefe ulaşırlar. Bir bakıma Platon'un sudurdan sonra aşkla yükseliş görüşü gerçekleşmiş olur. Hikâyenin ana kahramanlarından Leyla'nın hikâye sona ermeden ölmesi, Kays'ın amacına ulaşmasını sağlayarak artık işlevsiz hâle gelmesi neticesinde olsa gerektir. Hüsn ü Aşs'ın sonunda da Aşk Hüsn ile aynileştiğini görür. Bu iki mesnevideki kadın kahramanlar Kays ve Aşk'1 hakikate ulaştıran birer araçtan ibaret gözükmektedir. Bu bağlamda şairler adı geçen kadın kahramanların aşkını nasıl ele almıştır?

Çağlar boyunca şair ve yazarların büyük çoğunluğunun erkek olması nedeni ile geçmişle ilgili bize ulaşan tanımlamalar, tasvirler birer erkek gözlemi olarak ele alınmalıdır. Hemen hemen bütün mesnevi ve hikâyelerde anlatılan kadının aşkı bir erkeğin gözlemidir. Leyla'nın aşkı Fuzuli'nin ona çizdiği sınırlar içerisinde bize ulaşır. Mecnun'un pervasız aşkına karşın, Leyla'nın aşkı kadına çizilen sınırları aşmayacak, içsel bir aşk olarak resmedilir. Hikâyede Leyla'nın babasının arzusuna uyarak evlenmesi bize Leyla ile Kays'ın aşklarının ne kadar farklı bir tabiata sahip olduğunu gösterir. Buna karşılık Leyla’nın dilinden söylenilen gazellerde Leyla'nın aşkının Kays'tan çok farklı olmadığını görmek de mümkündür. Fuzuli hikâyenin genelinde Leyla'yı kollamış, onun aşkın yaşama şeklini onaylamış görünmektedir. 
Bununla birlikte Leyla aşkına Kays kadar sadık kalamamıştır. Annesi Leyla'nın âşı olduğunu fark edince, Leyla aşkını inkar etmiştir.

681 nâçâr dutup târik-i inkâr

Âsâr-1 tecahül etdi izhâr

(Çaresiz inkâr yolunu tutup

bilmiyormuş gibi yaptı).

682 Fül-zâr-1 itaba âb verdi

Giryân giryân cevâb verdi

(Cezalandırma gül bahçesine su verdi

çağlaya çağlaya cevap verdi).

(Doğan,2014a:46)

Orta çağ toplumlarında kadının toplumsal rolü sınırlı olduğu için, erkek kadar özgür karar verme ve kararların arkasında durma gücüne sahip değildi. Bu nedenle "inkar" kadının zorlandığ 1 durumlar için bir çıkış yolu olarak görülmüştür. Hüsn de aşkını dile getirememiştir. Hatta daye tavırlarından kuşkulanınca:

985 Bî-derde olur mu derd takrîr

Ez-cümle ola verâ-yı ta'bîr

(Dertsize dert anlatılmaz

gerisi bunun gibi tabir oluna)

(Doğan,2014b:65)

diyerek açıklama yapmayacağını ama muhatabın anlaması gerektiğini ima etmektedir. Yusuf u Züleyha mesnevisi yukarda adı geçen iki hikâyeden biraz daha farklı bir seyir izler. Yusuf u Züleyha hikâyesi Molla Cami'nin anlatımı ile Kur'an'daki en güzel kıssa övgüsüne layık romantik bir aşk hikâyesine dönüşmüştür. Kur'an'da adı bile anılmayan Züleyha Molla Cami’nin kaleminde büyük bir kahramana dönüşmüştür. Cami, Züleyha'nın aşkını daha bir kutsal zemine oturtmak için rüyada başlatmış, hikâyenin başlangıcında Züleyha daha Yusuf'u (as) görmeden âşık olmuştur. Leyla ve Hüsn gibi aşkını gizlemiş ve hâl ve tavrındaki değişiklik, yemeden içmeden kesilmesi gibi aşk belirtilerini neticesinde dadısı âşı olduğunu anlamıştır. Züleyha Mısır'a geldikten sonra daha muhteris bir âşık olmuş ve hikyenin seyri değişmiştir. Aşk için kınanmayı göze alan Züleyha, aşık kadına çizilen aşkını inkâr etme tanımlamasından kurtulamamış, Potifor ile Yusuf'u (as) konuşurken görünce kuşkulanıp, Yusuf'u şikayet etmekten ve aşkını gizlemekten çekinmemiştir.

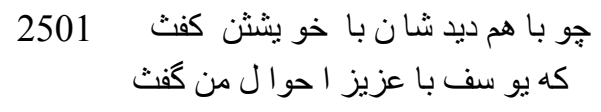


(Onları birlikte görünce kendine

dedi ki Yusuf Azizle benim hakkımda konuşuyor)

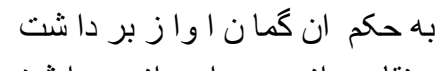

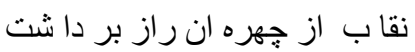

(Bu hükme binaen sesini yükseltti

Sırrının yüzündeki perdeyi kaldırdı)

(Afsadzad\&Tarbiyat,1997: 137)

Aşkı uğruna Mısır'a rezil olmayı göze almış Züleyha’nın bile zor durumda kalınca "inkâr" yolunu seçmesi Yusuf'u(as) suçlaması, erkekler nazarındaki kadının aşkının nasıl algılandığını gösteren dikkate değer bir örnek olarak düşünülebilir. Şair ve yazarların, kadınların aşkını tasvir ettikleri eserlerde kadınların hayatlarını şekillendiren toplumsal kuralları göz ardı etmedikleri görülmektedir. Aşk’ın erkek tarafı her türlü riski göze alıp, aşkın gereğini yerine getirirken kadın mütereddit hatta bazen "inkâr" durumundadır. Kadının aşkının bu ifade ediliş tarzı yalnızca İslam edebiyatı ürünleri için geçerli değildir. Batı edebiyatının en meşhur aşk hikâyesi olan Romeo ve Juliet'te de durum farklı değildir. Romeo, Juliet'in kuzenini öldürür ve ceza olarak şehirden sürgün edilir. Haberi alan Juliet çok üzülür ağlar. Romeo’yu göremeyecek olması onu etkiler. Ama annesi ansızın gelip, neden ağladığını sorunca kuzeni için ağladığını Romeo'yu öldürmek istediğini söyler. Batı kaynaklı bu aşk hikâyesinde de kadın âşık için "inkar", bir çıkış yolu olarak sunulmaktadır (Shakespeare, 2013:91).

Divân edebiyatı geleneğinde ve doğu kültüründe sevgilinin kadın olduğu eserlerde genel durum böyle olsa da sevgililerin erkek güzellerinden seçildiği şehrengizlerde, hikâye ve mesnevilerde de durum aynıdır. Sahnede olan, ağlayan, sızlayan, arayış yolculuğuna çıkan, aklını kaybeden, değişim ve dönüşüm geçiren hep âşıktır. Maşuk rolündeki kişi (erkek) hep sahne gerisindedir, genellikle pasif yapıdadır. Mesela Nergisi'nin, Meşakku'l-uşş'ak adlı on hikâyeden oluşan eserinde sevgili rolündeki kişiler erkek güzellerdir. Gerçek hayattan yola çıkılarak kaleme alınmış olan ve cinsellikten ziyade güzelliğin odak noktası olduğu bu hikâyelerde başrolde oynayan âşıklar, sevgiliye ulaşma yolunda canlarını ortaya koymakta, dayak yemekte, derbeder ve perişan bir hayat yaşamaktadırlar. Güzelliği ile âşıkları harekete geçiren bu güzeller, âdeta bir put gibi kendisine ulaşacak gözü kara âşıları beklemektedirler (Selçuk, 2009:66-71).

\section{Kadın Aşkı İçin Üzülür}

âteş-i '1şkest k'ender ney fütâd / cûşiş-i 1şkest k'ender mey fütâd (Neye düşmüş olan aşk ateşi ve meye düşmüş olan aşk coşkunluğudur.) (Avşar:2007) 
Aşkın ateşi şaraba, aşkın çoşkusu da neye düşmüştür der Mevlana. Ney gibi hüzünlü inlemek aşkın bileşenlerindendir. Aşkın erkek kahramanları her ortamda hüzünlerini yaşarken, kadın kahramanlar için bu o kadar kolay değildir. Hüsn der ki:

1057 Hey bu ne sitemdir Allah Allâh

Hem âteşe yan hem etme eyvâh

(Allah'1m bu ne sitemdir, hem ateşe yan hem de acıdan ağlama!)

(Doğan,2014b:73)

Kadın üzüntüyü aşkın sebep olduğu her türlü acıyı, kederi sessiz ve kimseye belli etmeden yaşamalıdır. Alenen yaşanacak bir aşk üzüntüsü kadının geleneklerle çizilmiş toplumsal imajını olumsuz etkileyecek, erkeğin aşkını hak eden temizliğinden feragat edilmiş olunacaktır. Burada şairler kadının aşkını tanımlarken kimi kısıtlamalarla karşı karşıya olduklarını söyleyebiliriz. Kadının nasıl üzülmesi gerektiği bir tanımlama ve tasvir etme sorunudur erkek yazarlar için. Fuzuli'yi bu konuda yaratıcıdır denilebilir. Leyla, gönül rahatlı̆̆ 1 ile aşkı uğruna ağlayabilmek için bedenine zarar verir.

1233 Ol terk kılup neşât u rahâtı

Bir uzvunu eyleyüp cerahât

(O sevinci ve rahatı terk edip

bir organını yaraladı)

1234 Eylerdi bahâne ile nâle

Düşmezdi olar düşen hayâle

(Bu bahane ile ağlardi, onların düştüğü hayale düşmezdi)

(Doğan,2014a:81)

Burada kadın ile erkeğin aşkının ifade ediliş tarzındaki farkı açıkça görmek mümkündür. Erkeğin aşkı için melamet bir onur iken, kadının tan edilmesi aşkının temiz kalmasına engel olarak görülmektedir. Kadın erkeğe yakışır bir aşkla sevmek ve iffetine söz ettirmeden aşkının acısını yaşamak durumundadır.

Aşkın yaşanması ve ifade edilmesi konusunda Züleyha bir hayli farklı bir konumdadır. Leyla vü ve Mecnun, Hüsn ü Aşk mesnevilerinin isimlerinden yola çıkarak şöyle bir şey söyleyebiliriz. Leyla Kays'1 Mecnun etmiştir. Hüsn'ün aşkı erkek kahraman olan Aşk'a büyük eziyetler çektirmiştir. Terakki süreci yaşayan Âşık ikinci isimdir hikâyede. Yusuf u Züleyha'da ikinci isim Züleyha'dır. Çünkü aşkı yaşayan ve terakki eden odur. Bir erkek kahraman gibi aşkını yaşamış ifade etmiştir. Aşkı uğruna melameti göze almıştır. Çünkü aşkının mükâfatı diğer 
hikâyelerdeki kahramanlarla kıyaslanmayacak kadar büyüktür. Bu nedenle melametle yoğrulup, olgunlaşması cismaniyetten sıyrılması gereken aşk Züleyha'nın aşkıdır. Hikâyenin diğer kahramanı olan Yusuf(as) peygamberdir. Aşkla terakki etmesi diye bir şey söz konusu olamaz. Oliver Leaman bu konuyu şöyle ifade eder:

“ Kur'an'da geçtiği hâliyle bu hikâyenin en ilginç özelliklerinden birisi Yusuf'un hiçbir şekilde değişmez oluşudur. Kralın emri ile zindandan kurtulması şansı varken bile kralın gerçekten suçsuzluğuna inanana kadar zindanı terk etmemekte 1srar etmesi bu durağanlığın örneklerinden birisidir. Yusuf sadece Yusuf olarak kendi bütünlüğünü muhafaza etmeye çalışır Gezegenlerin Aristoteles'in hareket etmeyen muhriklerin etrafinda dönmesi gibi, dünyanın geri kalanı da Yusuf'un etrafinda döner ( Leaman, 2010:143).

Yusuf'un (as) bu durağan hâli diğer mesnevilerdeki kadın kahramanların durumu gibidir. Erkek kahraman dünyayı dolaşır, ordularla savaşır ama kadın kahraman yüksek duvarlarla çevrilmiş mekânlarda aşı̆̆ını uzaktan izler. Züleyha, aşkta terakki edince yani fiziki güzelliğe aşkı aşıp, gerçeğe ulaşınca her şey değişir. Hikâye gerçek bir sona ulaşır. "Züleyha, fiziki güzelliğin sadece bir put olduğunu öğrenir öğrenmez ve bunu paramparça etmeyi başarır başarmaz kendi güzelliği de geri gelir ve hayatı boyunca ulaşmaya çalıştığını nihayet elde eder..." (Leaman:2010:143).

Aşk, gerçeğe ulaşmanın bir yolu olarak görülmüştür. Bu gerçek tasavvufta tek gerçek olarak görülen Tanrı'nın kedisinden başka bir şey değildir.

\section{SONUÇ}

Aşk, insanlık tarihinin en büyük ve en devamlı üretimi olan edebiyatın en temel teması, en önemli konusudur. İstisnasız bütün diller ve edebiyatlar için tükenmez bir kaynaktır. Semavi dinler için aşk dini bir renge sahip, tarihsel kökleri olan bir konudur. İslam kültüründe özellikle tasavvufta aşk, yaratılışın döngüsü içerisinde yükselişi sağlayan yegâne araç olarak görülmektedir. Aşkın ikinci tarafının terakkisi çoğu hikâyede ihmal edilmiştir. Erkek kahraman aşkla olgunlaşıp, mecazdan hakikate geçerken kadın kahramanın varlığının hikâyede önemsiz hâle geldiği görülmektedir. Kadın kahraman erkeğin aşkla terakkisi için bir araç görevi görmektedir denilebilir. Ele aldığımız üç mesnevinin ikisinde kadın kahramanlar benzer özelliğe sahiptir. Yusuf u Züleyha'da ise durum farklıdır. Züleyha bir erkek kahraman gibi hikâyede aşkla terakki eden taraftır. 
Kayabaşı, B. / Sosyal Bilimler Araştırmaları Dergisi. II, (2014): 32-42

\section{KAYNAKLAR}

Arslanoğlu, İ. (t.y.), Mevlâna'nın Aşk ve İnsan Felsefesi. http://w3.gazi.edu.tr/ iarslan/mevlanaaskinsan.pdf, (E.T.: 29.11.2014).

Avşar, Z. (2007), "Ruhu'l-mesnevi'de Mesnevi'nin ilk 18 beytin Şerh Yöntemi” Turkish Studies / Türkoloji Araştırmaları, 2(3).

Aydın, H. (2013), Mitos'tan Logos'a Eski Yunan Felsefesinde Aşk. Bilim ve Gelecek Kitaplığı. Ayvazoğlu, B. (1989), İslam Estetiği ve İslam. Çağ Yayınları.

Birgül, M. F. (2000), Aşk Risaleleri. Sır Yayıncılık.

Chittick, W. (2008), Tasavvuf: Kısa Bir Giriş. İstanbul: İz Yay.

Doğan, M. N. (2014a), Leyla vü Mecnun. http://ekitap.kulturturizm.gov.tr/Eklenti/10679,girispd f.pdf (E.T.: 25.11.2014).

Doğan, M. N. (2014b), Hüsn ü Aşk. http://ekitap.kulturturizm.gov.tr/Eklenti/10711,seyhgalibhusnuaskmuhammetnurdoganp df.pdf (E.T.: 25.11.2014).

Kılıç, C. (2009), "Plotinus'ta Sudurla İnen ve Aşkla Yükselen Çift Kutuplu Hakikat Anlayışı". Kelam Araştırmaları Dergisi, 7(1). ss. 39-56.

Kramer, S. N. (1999), Tarih Sümer'de Başlar. (Çev: Hamide Koyukan). İstanbul: Kabalcı Yay.

Leaman, O. (2010), İslam Estetiğine Giriş. (Çev: Nuh Yılmaz). İstanbul: Küre Yay.

Özlem, D. (2004), Klasik Sembolik Mantık, Mantık Felsefesi. İstanbul: İnkılap Kitapevi

Shakespeare, W. (2013), Romeo ve Juliet. (Çev: Nutku Özdemir). İstanbul: Hasan Ali Yücel Klasikleri.

Selçuk, B. (2009), Nergisi Meşakku'l-uşşak. Erzurum: Salkımsöğüt Yay.

Taşkent, A. (2009), Farabi, İbn Sina, İbn Rüşd'de Estetik. Basılmamış Doktora Tezi. Marmara Üniversitesi Sosyal Bilimler Enstitüsü

Uludağ, S. (1991), “Aşk". Diyanet Vakfı İslam Ansiklopedisi, C.4, İstanbul: TDV Yay., ss. 430463

Yalar, M. (2005), "Câhiliyenin kavramsal ve tarihsel mahiyeti ışığında şiirinin sosyal arka planı”. Uludağ Üniversitesi İlahiyat Fakültesi Dergisi, 14 (2), s. 75-95.

Yünügül, S. (2007), İhvan-1 Safa ve İbn Sina'da Aşk-Güzellik İlişkisi. Yüksek Lisans Tezi. Erciyes Üniversitesi Sosyal Bilimler Enstitüsü

Yörükan, T. (2006), Yunan Mitolojisinde Aşk. İstanbul: Ebabil Yayıncılık.

Nur al-Din 'Abd al-Rahman ibn Ahmad Jami (1997). Haft owrang, Yosuf zoleyxa, Leyli\&Majnun and Xeradname-ye Eskandari, (Edited by, A. Afsahzad\%H.A. tarbiyat).

Center For Iranian Stydies, Tehran 1997. www.al-mostafa.com, Resailu Ihvanu's-safa 